\title{
NURSING MANAGEMENT IN PATIENTS WITH VASCULER ACCESS (PERIPHERAL INTRAVENOUS CATHETERIZATION) FOR BURNS
}

F.ŞAHIN* , F.İÇLI* , E.SÜSLÜ* , M.DERELI* , S.ÇİL*, S.KARAKAPLAN**,M.SEYYAH *, G.FILINTE *

*Health Sciences University Kartal Dr.Lutfi Kirdar Training and Research Hospital Wound and Burn Treatment Center.İstanbul/ TURKEY

**Health Sciences University Kartal Dr.LütfiKırdar Training and Research Hospital Health Care Services Manager.Istanbul/ TURKEY

OBJECTIVE: Nursing management is important in cases with severe peripheral intravenous catheterization due to burns. Factors such as stress caused by previous trauma, anxiety of the relatives of the patients, the characteristics of the pediatric case and the excess of the dressing area have a negative effect on the presence of suitable veins

ABSTRACT: Peripheral intravenous catheterization is the placement of the intravenous catheter in the peripheral vein lumen. Peripheral intravenous catheterization is one of the most common invasive procedures of the nurse. They play a very important role in the success of this initiative and in ensuring the continuity of implementation. Peripheral intravenous catheterization is a difficult skill to obtain in terms of health professionals, which is even more difficult when the child and baby are involved.

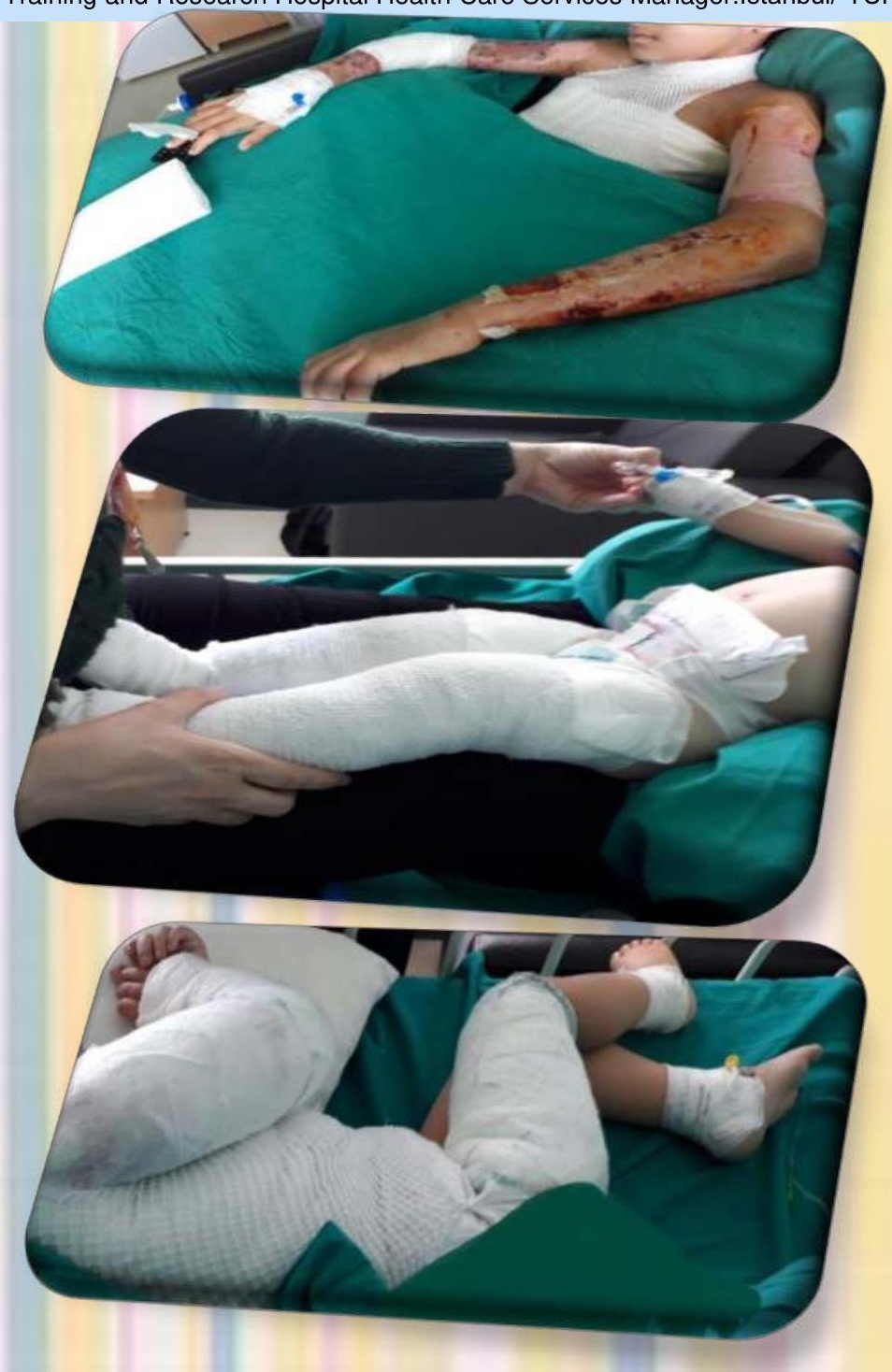

RESULTS:In our Wound and Burns Treatment Center, 60 patients under 3 years of age and treated were examined ;

40 patients were successfully opened by our peripheral intravenous catheterization nurses. Central venous catheter was inserted in 15 patients. 5 patients were opened with the support of nurses working in the Children's Department.

DISCUSSION:Burn Due to the existing burns in pediatric and pediatric cases, almost all body areas are covered with dressing by dressing, and there are difficulties due to the fact that there is very little area of the burn area and it is not available in these areas.

It is even more difficult to open the cannula by reasons such as the higher fear and stress experienced in burned child and infant cases, the occurrence as an unusual situation, the high number of unknowns, and the anxiety of the family and relatives.

CONCLUSION: It is inevitable that the incision of forced peripheral percutaneous intravenous catheterization is inevitable. The number of experienced burn nurses can be planned to be increased and certified. 